\title{
Pteridaceae endémicas del Perú
}

\author{
Blanca León ${ }^{1,2}$
}

${ }^{1}$ Museo de Historia Natural, Av. Arenales 1256, Aptdo. 14-0434, Lima 14, Perú

2 Plant Resources Center, University of Texas at Austin, Austin TX 78712 EE.UU.

blanca.leon@mail.utexas.edu

\section{Resumen}

Esta familia es reconocida en el Perú con 18 géneros y más de 150 especies (Tryon \& Stolze, 1989b; Smith et al., 2005). Si bien la familia Pteridaceae es la más rica en especies de la flora pteridofítica peruana; solamente ocho especies en cuatro géneros se reconocen como endémicas. Todos los endemismos son plantas terrestres que ocupan principalmente ambientes subxéricos y abiertos de las regiones ecológicas del Matorral Desértico y Mesoandina, entre los 500 y 3500 m de altitud. Solamente, una de las ocho especies cuenta con poblaciones en un área protegida.

Palabras claves: Pteridaceae, Perú, endemismo.

\section{Abstract}

This family is recognized in Peru with 18 genera and more than 150 species (Tryon \& Stolze, 1989b; Smith et al., 2005). Although the Pteridaceae is the most species rich family in the Peruvian flora, only eight species in four genera are recognized as endemics. All endemic species are terrestrial plants occupying open areas in the Desert Shrubland and Mesoandean regions, between 500 and 3500 m elevation. Only one taxon is found in a protected area.

Keywords: Pteridaceae, Peru, endemism.

\section{Adiantum imbricatum R.M. Tryon}

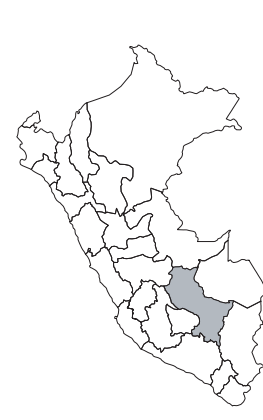

$$
\text { EN, B1a }
$$

Publicación: Amer. Fern J. 47: 142, t. 15. 1957.

Colección tipo: C. Bües 1377

Herbarios: F, GH, US; CUZ!, USM!.

Nombre común: Desconocido.

Registro departamental: CU.

Regiones Ecológicas: MDE; 1600—2000 m.

SINANPE: Sin registro.

Herbarios peruanos: CUZ (isotipo), USM (isotipo).

Observaciones: Esta especie terrestre se conoce sólo de tres colecciones, realizadas en 1923, en una subcuenca del Urubamba. Poco se sabe de las poblaciones; se conoce que ocupa ambientes semixéricos, los que en todo el país requieren de mayor exploración y estudio botánico.

\section{Argyrochosma stuebeliana (Hieron.) Windham}

\section{NT}

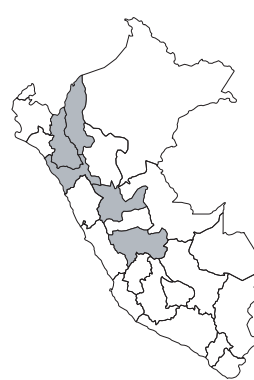

Publicación: Amer. Fern J. 77: 41. 1987. Colección tipo: A. Stübel 1048 p.p. Herbarios: B.

Nombre común: Desconocido. Registro departamental: AM, CA, HU, JU, LL.

Regiones Ecológicas: MA, BS; 1800$3000 \mathrm{~m}$.

SINANPE: Sin registro.

Herbarios peruanos: HUT (2), USM (1).

Observaciones: Esta especie terrestre se conoce, principalmente, de las cuencas altas y medias del Huallaga, Marañón y Utcubamba. Su rango de distribución podría extenderse a otras subcuencas con ambientes semixéricos. Esta especie pasa desapercibida, por su hábitat y la producción estacional de sus hojas.

\section{Cheilanthes cantangensis (R.M. Tryon) R.M. Tryon}

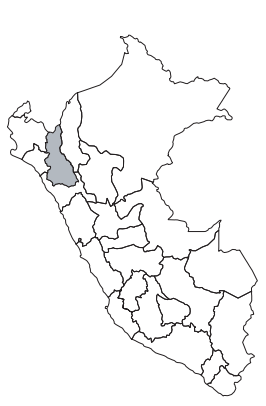
CR, B1ab(iii)

Publicación: Fieldiana Bot., n.s. 22: 32. 1989.

Colección tipo: A. López M. \& A. Sagástegui A. 3366

Herbarios: GH; HUT.

Nombre común: Desconocido.

Registro departamental: CA.

Regiones Ecológicas: BS; $1450 \mathrm{~m}$.

SINANPE: Sin registro.

Herbarios peruanos: HUT (isotipo).

Observaciones: Este helecho terrestre, se conoce solamente de una localidad, en la cuenca del río Marañón. Aparentemente, no ha vuelto a ser recolectada desde la década de 1960, tal vez, por pasar desapercibida, en las laderas semixéricas que ocupa.

\section{Cheilanthes fractifera R.M. Tryon}

$$
\text { VU, B1a }
$$

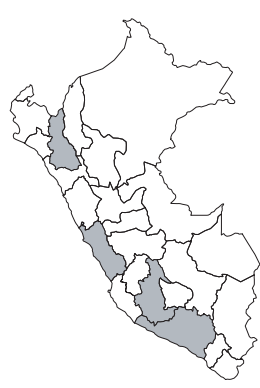

Publicación: Rhodora 62: 7, t. 1252. 1960. Colección tipo: D.S. Correll \& E.E. Smith P169

Herbarios: GH, TEX-LL.

Nombre común: Desconocido.

Registro departamental: AR, AY, CA, LI. Regiones Ecológicas: MDE, MA; 1600$2200 \mathrm{~m}$.

SINANPE: Sin registro.

Herbarios peruanos: HUT (1), USM (3).

Observaciones: Este helecho terrestre se conoce de siete localidades, naturalmente fragmentadas y dispersas en la vertiente del Pacífico.Sus poblaciones ocupan matorrales o herbazales abiertos, en laderas expuestas y rocosas. 


\section{Cheilanthes lonchophylla (R.M. Tryon) R.M. Tryon \& A.F. Tryon

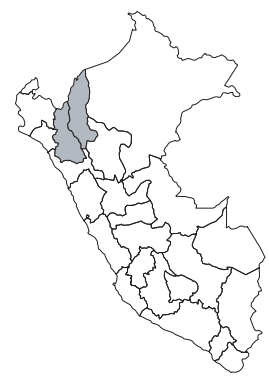 \\ EN, B1a \\ Publicación: Rhodora 83: 133. 1981. \\ Colección tipo: A. Mathews 610 \\ Herbarios: K. \\ Nombre común: Desconocido. \\ Registro departamental: AM, CA. \\ Regiones Ecológicas: MA; 2850—2950 $\mathrm{m}$. \\ SINANPE: Sin registro. \\ Herbarios peruanos: HAO (3), HUT (2).}

Observaciones: Helecho terrestre conocido de la vertiente del Pacífico y valles secos del Marañón. Esta especie habita ambientes con estaciones de lluvia marcadas; probablemente la producción foliar responda a esta estacionalidad.

\section{Cheilanthes peruviana (Desv.) T. Moore}

\section{LC}

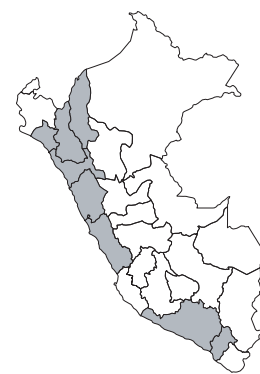

Publicación: Index fil. 250. 1861.

Colección tipo: J. Dombey s.n.

Herbarios: B, K, P.

Nombre común: Desconocido.

Registro departamental: $\mathrm{AM}, \mathrm{AN}, \mathrm{AR}$, CA, LL, LA, LI, MO.

Regiones Ecológicas: DST, MA; 500$3200 \mathrm{~m}$.

SINANPE: Sin registro.

Herbarios peruanos: CPUN (1), HUT $(>10)$, USM (12).

Observaciones: Este helecho terrestre es de amplia distribución en el occidente del país y ambientes semixéricos interandinos, como la cuenca del Marañón. Tryon \& Stolze (1989) indicaron el estatus taxonómico incierto de esta especie, pero aquí se la acepta.

\section{Eriosorus accrescens A.F. Tryon}

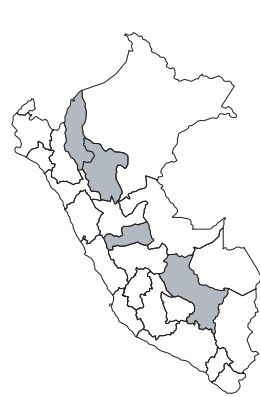

\section{NT}

Publicación: Rhodora 65: 57. 1963.

Colección tipo: C. Vargas C. 2921

Herbarios: MO, US.

Nombre común: Desconocido.

Registro departamental: AM, CU, PA, SM.

Regiones Ecológicas: BPM, BMHM; $2800-3500 \mathrm{~m}$.

SINANPE: PNRA, PNYC

Herbarios peruanos: AMAZ (1), HUT (2), USM (9).

Observaciones: Helecho terrestre, de hojas escandentes, conocida de varias localidades aisladas, en cuencas de la vertiente oriental. Esta es una especie que ocupa ambientes ecotonales pajonal-bosque y en quebradas protegidas.

\section{Eriosorus wurdackii A.F. Tryon}

\section{CR, B1a}

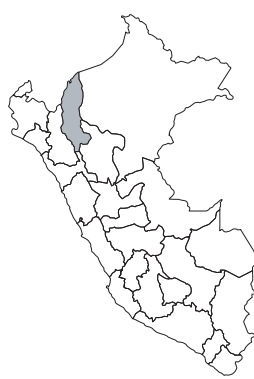

Publicación: Contr. Gray Herb. 200: 147. 1970.

Colección tipo: J.J. Wurdack 1541

Herbarios: GH, US; USM!

Nombre común: Desconocido.

Registro departamental: AM.

Regiones Ecológicas: PAR; 2200—2300

$\mathrm{m}$.

SINANPE: Sin registro.

Herbarios peruanos: USM (isotipo).

Observaciones: Este helecho terrestre se conoce solamente de una localidad, en la cuenca del Utcubamba y en ambientes de jalca. $\mathrm{Al}$ parecer, no ha vuelto a ser recolectada desde 1962. Se considera a esta especie en estado crítico, aunque su estatus taxonómico debe ser evaluado. 